\title{
ASSOCIATION BETWEEN ARTERIOVENOUS FISTULAE AND HEMATOMAS IN A DIALYSIS CENTER IN THE STATE OF RIO GRANDE DO SUL, SOUTHERN BRAZIL
}

\author{
Regina Helena Medeiros ${ }^{1}$, Thiago Pereira Kovalski ${ }^{1}$, \\ Sandie Lauren Kahl Mueller Kovalski ${ }^{1}$, Clenice Pudlo ${ }^{1}$, Cristiani Sarro', \\ Jane Maria Cornelli ${ }^{1}$, Luciano da Silva Selistre ${ }^{2}$, Jonas Michel Wolf ${ }^{3}$, \\ Vagner Reinaldo Zingalli Bueno Pereira ${ }^{1,3}$
}

\section{ABSTRACT}

Introduction: Chronic kidney disease (CKD) is characterized by slow, progressive, and irreversible loss of kidney function. CKD has become a serious public health issue because of its increasing morbidity and mortality rates. The present study aimed to investigate factors associated with hematomas caused by arteriovenous fistula (AVF) at a Renal Replacement Therapy Unit in the state of Rio Grande do Sul, southern Brazil.

Methods: In this cross-sectional study, 72 patients with CKD aged 18 years or over, presenting with AVF, and undergoing three hemodialysis sessions per week were evaluated from June 2014 to March 2015. Prevalence ratios (PRs) with 95\% confidence intervals $(95 \% \mathrm{Cls})$ were estimated for identification of risk factors associated with AVF. $P$-values $<0.05$ were considered significant.

Results: Sex, age, self-reported skin color, educational level, hypertension, diabetes, nephrotic syndrome, congestive heart failure, and hepatitis $\mathrm{C}$ were not associated with hematoma formation (i.e., all estimated PRs had $p$-values $>0.05$ ). The single factor associated with hematomas was AVF time shorter than 60 days (PR $=2.04 ; 95 \% \mathrm{Cl}: 1.28-3.27 ; p<0.01)$.

Conclusion: AVF maturation time was associated with higher prevalence of hematomas at the cannulation site. Therefore, AVF time should be given special attention in patients undergoing renal therapy at dialysis centers.

Keywords: Arteriovenous fistula; hematoma; chronic renal failure

Chronic kidney disease (CKD) is characterized by slow, progressive, and irreversible loss of kidney function with biochemical and physiological deterioration of the renal system, leading to accumulation of toxins in the body and hydroelectrolytic and hormonal unbalance ${ }^{1-2}$. CKD diagnosis is defined as glomerular filtration rate (GFR) $<60 \mathrm{~mL} / \mathrm{min} / 1.73 \mathrm{~m}$ or GFR $\geq 60 \mathrm{~mL} / \mathrm{min} / 1.73 \mathrm{~m}$ in patients with a marker of renal parenchymal damage (e.g., albuminuria) for more than 3 months $^{2-4}$. CKD has become a public health issue because of its increasing morbidity and mortality rates as well as high maintenance costs of renal replacement therapies, such as hemodialysis, peritoneal dialysis, and kidney transplantation'.

According to global health estimates, CKD accounted for 864,226 deaths (i.e., $1.5 \%$ of all deaths worldwide) in 2012 , being the 14 th leading cause of deaths that year ${ }^{5}$. In Brazil, current data show that mortality due to CKD is approximately $15 \%$ in renal replacement therapy services ${ }^{6}$. The major contributing cause of mortality in this group of patients is cardiovascular disease, regardless of other classic risk factors such as age, ethnicity, sex, and underlying comorbidities (e.g., diabetes) ${ }^{6}$.

Clin Biomed Res. 2018;38(3):253-257

1 Hospital Geral de Caxias do Sul, Universidade de Caxias do Sul (UCS). Caxias do Sul, RS, Brasil.

2 Programa de Pós-graduação em Ciências da Saúde, Universidade de Caxias do Sul (UCS). Caxias do Sul, RS, Brasil.

3 Programa de Pós-graduação em Biologia Celular e Molecular Aplicada à Saúde, Universidade Luterana do Brasil (ULBRA). Canoas, RS, Brasil.

Corresponding author: Jonas Michel Wolf jonasmwolf@gmail.com Universidade Luterana do Brasil (ULBRA)

Av. Farroupilha, 8001

92425-900, Canoas, RS, Brasil. 
In patients with CKD, conventional hemodialysis can be performed through different types of vascular access, including central venous catheter and arteriovenous fistula (AVF) ${ }^{7}$. An AVF consists of a subcutaneous anastomosis between an artery and an adjacent vein, with dilation of superficial veins, allowing constant circulation and repeated needle insertion ${ }^{8,9}$.

A major complication in AVF management is post-cannulation hematoma. Hematomas may present with several forms according to a patient's hemostatic state as well as blood volume and time of blood confinement at the cannulation site ${ }^{7,8}$. Period of cannulation, use of anticoagulation, and dose and type of anticoagulant are factors which contribute to hematoma formation ${ }^{8,9}$. Thus, an adequate cannulation technique is essential for preventing AVF hematomas. Hematomas are a major complication because they impair the process of cannulation and, therefore, dialysis, affecting directly the quality of life of a patient with kidney disease. In addition, hematomas contribute to complications such as AVF thrombosis and stenosis ${ }^{8,9}$.

The present study aimed to investigate factors associated with AVF hematomas at a teaching hospital's Renal Replacement Therapy Unit (RRTU) in the state of Rio Grande do Sul, southern Brazil, in the period of 2014-2015.

\section{METHODS}

\section{Design and Location}

This retrospective, cross-sectional study was conducted at a teaching hospital's RRTU in a municipality located in the state of Rio Grande do Sul. The hospital is a referral center for 49 nearby municipalities. Users are covered by the Brazilian Unified Health System (Sistema Único de Saúde, SUS).

\section{Inclusion Criteria and Data Collection}

The following inclusion criteria were used: patients with CKD, aged 18 years or over, presenting with AVF, and undergoing three hemodialysis sessions per week, from June 2014 to March 2015. Data were collected from a RRTU spreadsheet containing indicators measuring the monthly risk of hematoma formation due to AVF. This instrument included the following variables: sex, age, self-reported skin color, educational level, occupation, AVF time, professional in charge of AVF cannulation, and length of experience of this professional. In addition, it informed whether a patient had the following comorbidities: hypertension, diabetes, nephrotic syndrome, congestive heart failure, and hepatitis $C$.

\section{AVF Creation and Anticoagulation During Dialysis}

In all patients, AVF was created using Nipro Medical Corporation ${ }^{\circledR} 17 \mathrm{G}$ needles. Anticoagulation was performed at the beginning of dialysis using a bolus of heparin according to each patient's body weight and coagulation state, with doses ranging from 2000 to $5000 \mathrm{UI} / \mathrm{mL}$. The process of dialysis lasted for approximately 4 hours.

\section{Sample Size Calculation}

Epi Info ${ }^{\mathrm{TM}}$ software was used for estimating the size of the study sample, considering an expected outcome prevalence of $40 \%{ }^{10}$, a maximum error of $\pm 4 \%$, and a confidence level of $95 \%$. Thus, the initial sample size was calculated at 65 patients. To compensate for losses, the sample was increased by $10 \%$, resulting in a total of 72 patients.

\section{Ethical Considerations}

This study was conducted in accordance with regulatory standards and guidelines of research involving humans, as defined by resolution no. 466/2012 of the Brazilian National Health Council (protocol no. 37/2014).

\section{Statistical Analysis}

Data were analyzed using IBM SPSS ${ }^{\circledR}$ software, version 23.0. For continuous data, normality was assessed using Kolmogorov-Smirnov test, with Lilliefors correction. Student's t-test for independent samples was used for assessing possible differences between mean values in the study groups. Prevalence ratios (PRs) with 95\% confidence intervals $(95 \% \mathrm{Cls})$ were estimated. Categorical data were described as absolute and percentage frequencies, then compared between groups using Pearson's chi-square test or Fisher's exact test, as appropriate. $P$-values $<0.05$ were considered significant, and all tests were two-tailed.

\section{RESULTS}

Of all participants $(n=72), 61.1 \%$ were male. Mean age was $59 \pm 15.5$ years, ranging from 20 to 84 years. Most participants were older than 60 years $(54.2 \%)$. The sample consisted mainly of self-reported white people $(73.6 \%)$ with less than 8 years of education $(94.4 \%)$ and employed in the metallurgical industry $(20.8 \%)$ (Table 1). 
Table 1: Sociodemographic characteristics of patients treated at a Renal Replacement Therapy Unit in southern Brazil between 2014 and 2015.

\begin{tabular}{lcc}
\hline \multicolumn{1}{c}{ Variable } & $\mathbf{n}=\mathbf{7 2}$ & $\%$ \\
\hline Sex & & \\
$\quad$ Male & 44 & 61.1 \\
$\quad$ Female & 28 & 38.9 \\
Age (years) & & \\
$\geq 61$ & 39 & 54.2 \\
$20-60$ & 33 & 45.8 \\
Self-reported skin color & & \\
$\quad$ White & 53 & 73.6 \\
$\quad$ Non-white & 19 & 26.4 \\
Educational level & & \\
$\quad$ 8 years of education & 68 & 94.4 \\
$\quad$ > years of education & 4 & 5.6 \\
Occupation & & \\
$\quad$ Metalworker & 15 & 20.8 \\
$\quad$ Unemployed & 7 & 9.7 \\
Production assistant & 7 & 9.7 \\
$\quad$ Self-employed & 5 & 6.9 \\
Other & 38 & 52.8 \\
\hline
\end{tabular}

Hemodialysis service staff included four registered nurses with mean length of experience of $10.2 \pm 1.25$ years and 26 licensed practical nurses with mean length of experience of $2.1 \pm 2.19$ years, which was a significant difference $(p<0.01)$. Of the 9 hematomas identified in the sample, $1(11.1 \%)$ was cannulated by a registered nurse and $8(89.9 \%)$ were cannulated by licensed practical nurses (PR $=1.03 ; 95 \% \mathrm{Cl}: 0.77-1.38 ; p=0.82)$.

A comparison between sociodemographic variables and comorbidities which could be associated with hematoma formation due to AVF is demonstrated in Table 2. No variable was associated with hematoma formation (i.e., all estimated PRs had $p$-values $>0.05)$, except for AVF time shorter than 60 days (PR $=2.04 ; 95 \% \mathrm{Cl}: 1.28-3.27 ; p=0.03$ ), which was more common in the hematoma group (Table 2).

Table 2: Comparison of sociodemographic variables and risk factors in patients with or without hematomas (yes/no) treated at a Renal Replacement Therapy Unit in southern Brazil between 2014 and 2015.

\begin{tabular}{|c|c|c|c|c|c|c|}
\hline \multirow{2}{*}{ Variable } & \multicolumn{2}{|c|}{ Yes $(n=31)$} & \multicolumn{2}{|c|}{ No $(n=41)$} & \multirow{2}{*}{ PR $(95 \% \mathrm{Cl})$} & \multirow{2}{*}{$p$-value* } \\
\hline & $\mathbf{n}$ & $\%$ & $\mathbf{n}$ & $\%$ & & \\
\hline \multicolumn{7}{|l|}{ Sex } \\
\hline Male & 17 & 54.8 & 27 & 65.9 & $0.77(0.46-1.31)$ & 0.34 \\
\hline Female & 14 & 45.2 & 14 & 34.1 & 1.00 ref. & \\
\hline \multicolumn{7}{|l|}{ Age (years) } \\
\hline$\geq 61$ & 16 & 51.6 & 23 & 56.1 & $0.90(0.53-1.53)$ & 0.71 \\
\hline $20-60$ & 15 & 48.4 & 18 & 43.9 & 1.00 ref. & \\
\hline \multicolumn{7}{|l|}{ Self-reported skin color } \\
\hline White & 25 & 80.6 & 28 & 68.3 & $1.49(0.73-3.07)$ & 0.24 \\
\hline Non-white & 6 & 19.4 & 13 & 31.7 & 1.00 ref. & \\
\hline \multicolumn{7}{|l|}{ Educational level } \\
\hline$<8$ years of education & 30 & 96.8 & 38 & 92.7 & $6.6(0.98-44.79)$ & 0.63 \\
\hline$>8$ years of education & 1 & 3.2 & 3 & 7.3 & 1.00 ref. & \\
\hline \multicolumn{7}{|l|}{ Hypertension } \\
\hline Yes & 19 & 61.3 & 25 & 61.0 & $1.01(0.58-1.73)$ & 0.98 \\
\hline No & 12 & 38.7 & 16 & 39.0 & 1.00 ref. & \\
\hline \multicolumn{7}{|l|}{ Diabetes } \\
\hline Yes & 7 & 22.6 & 14 & 34.1 & $0.71(0.36-1.38)$ & 0.29 \\
\hline No & 24 & 77.4 & 27 & 65.9 & 1.00 ref. & \\
\hline \multicolumn{7}{|l|}{ Nephrotic syndrome } \\
\hline Yes & 5 & 16.1 & 4 & 9.8 & $1.34(0.70-2.60)$ & 0.42 \\
\hline No & 26 & 83.9 & 37 & 90.2 & 1.00 ref. & \\
\hline \multicolumn{7}{|l|}{$\mathrm{CHF}$} \\
\hline Yes & 4 & 12.9 & 2 & 4.9 & $1.63(0.86-3.07)$ & 0.22 \\
\hline No & 27 & 87.1 & 39 & 95.1 & 1.00 ref. & \\
\hline \multicolumn{7}{|l|}{ Hepatitis C } \\
\hline Yes & 1 & 3.2 & 1 & 2.4 & $1.16(0.28-4.78)$ & 0.84 \\
\hline No & 30 & 96.8 & 40 & 97.6 & 1.00 ref. & \\
\hline \multicolumn{7}{|l|}{ AVF time } \\
\hline$\leq 60$ days & 7 & 22.6 & 2 & 4.9 & 2.04 (1.28-3.27) & 0.03 \\
\hline$>60$ days & 24 & 77.4 & 39 & 95.1 & 1.00 ref. & \\
\hline
\end{tabular}




\section{DISCUSSION}

The present study evaluated variables possibly associated with hematomas in patients with AVF undergoing hemodialysis at a teaching hospital's RRTU in Rio Grande do Sul. Sex, age, self-reported skin color, educational level, hypertension, diabetes, nephrotic syndrome, congestive heart failure, and hepatitis $C$ were not statistically associated with hematoma formation. Nonetheless, presence of hematomas was associated with AVF time, suggesting caution in AVF management in patients undergoing hemodialysis.

According to the literature, variables such as age, educational level, diabetes, peripheral vascular disease, hypertension, coagulopathy, obesity, and smoking affect AVF maturation time and hematoma formation ${ }^{7,8,11-14}$. Consistent with our results, Lee et al. $(2006)^{11}$ prospectively studied AVF infiltration in the United States and found no association of sex, race, and diabetes with occurrence of hematomas. However, in the same study, age was associated with hematomas ${ }^{11}$. No statistical association between educational level and presence of hematomas was found in the present study. Conversely, low educational level has already been associated with hematomas in patients with AVF in a study conducted in southern Brazil ${ }^{12}$. Furthermore, other studies have described low educational level as a risk factor for AVF complications ${ }^{7,13,14}$. The finding that most patients undergoing hemodialysis and showing complications have low educational level suggests that those with higher educational levels tend to seek health services earlier and practice self-care ${ }^{15,16}$. Additionally, age is an important factor for predisposition of hematomas in patients with $\mathrm{AVF}^{11}$, as the older the patient, the higher the likelihood of achieving this outcome, as a result of the aging process affecting the tunica intima of blood vessels ${ }^{16}$. This situation suggests that, with aging, vessels become fragile and, therefore, more susceptible to hematomas. However, this association was not found in the present study.

The cannulation method used in the present study for AVF access was the rope ladder technique, which rotates puncture sites in order to prevent formation of aneurysms, hematomas, and stenoses due to repeated damage to the vessel wall ${ }^{17,18}$. Cannulation care includes vascular access techniques, needle size, level of difficulty, and knowledge of what may cause hematomas, which can be developed through continuing education at health services ${ }^{14,18,19}$. Of the patients presenting with AVF hematomas, 6 (19.3\%) had their AVF discontinued, requiring the use of a Shiley catheter for hemodialysis. Seven (22.6\%) patients had AVF maturation time shorter than 60 days. In several high-income countries, mean time for utilization of a fistula exceeds 60 days (98 days in the United States, 80 days in Spain, and 86 days in France). The few countries which have reported early AVF use are Japan ( 25 days) and Italy (27 days) ${ }^{20}$. Data show that insufficient AVF maturation contributes to hematoma formation ${ }^{20}$. Ideal maturation time would be longer than 60 days, but certain medical situations require early AVF use ${ }^{21}$. As hematomas frequently occur in the early stages of use of a fistula, the first cannulation should be performed by an experienced nurse ${ }^{22}$. Experienced nurses are capable of successfully predicting AVF maturation in $80 \%$ of the cases ${ }^{17-21}$. Thus, technical expertise and length of experience of the nurse in charge of creating an AVF is another relevant variable for reducing complications in hemodialysis access procedures ${ }^{13,17-19}$. In the present study, despite the lack of statistically significant difference probably because of the small sample size, the difference between number of hematomas in cannulations performed by registered nurses (11.1\%) and number of hematomas in cannulations performed by licensed practical nurses (89.1\%) was relevant. This finding reinforces that training and length of professional experience are essential for preventing hematomas.

The limitations of this study include its retrospective nature and sample size with low statistical power $(n=72)$. However, the present results may be useful for managing AVF time, with the aim of reducing hematoma formation and thus contributing to improving the quality of life of patients undergoing hemodialysis. Furthermore, future studies such as prospective cohorts with larger samples, more data on patients' hemostatic state, and a wider scope of collected variables should provide greater understanding of AVF complications in patients undergoing hemodialysis.

\section{CONCLUSION}

AVF maturation time shorter than 60 days increases substantially the prevalence of hematomas at the cannulation site. Centers providing hemodialysis treatment must be aware of this finding.

\section{Conflicts of Interest}

The authors declare no conflicts of interest. 


\section{REFERENCES}

1. Jha V, Garcia-Garcia G, Iseki K, Li Z, Naicker S, Plattner B, et al. Chronic kidney disease: global dimension and perspectives. Lancet. 2013;382(9888):260-72. http://dx.doi. org/10.1016/S0140-6736(13)60687-X. PMid:23727169.

2. Webster AC, Nagler EV, Morton RL, Masson P. Chronic Kidney Disease. Lancet. 2017;389(10075):1238-52. http://dx.doi.org/10.1016/S01406736(16)32064-5. PMid:27887750.

3. Bastos M, Kirsztajn G. Doença renal crônica: importância do diagnóstico precoce, encaminhamento imediato e abordagem interdisciplinar estruturada para melhora do desfecho em pacientes ainda não submetidos à diálise. J Bras Nefrol. 2011;33(1):93108. http://dx.doi.org/10.1590/ S0101-28002011000100013. PMid:21541469.

4. National Kidney Foundation. K/ DOQI Clinical Practice Guidelines for Chronic Kidney Disease: evaluation, classification and stratification. $\mathrm{Am} \mathrm{J}$ Kidney Dis. 2002;39(2 Suppl 1):S1266. PMid:11904577.

5. World Health Organization (WHO). Mortality and global health estimates: Causes of death; Projections for 2015-2030; Projection of death rates. Geneva: WHO; 2018 [cited 2018 May 10]. Available from: http://apps.who. int/gho/data/node.main

6. Ferraz FHRP, Martins CGB, Cavalcanti JC, Oliveira FL, Quirino RM, Chicon R, et al. Profile of glomerular diseases in a public hospital of Federal District, Brazil. J Bras Neurol. 2010;32(3):24956. http://dx.doi.org/10.1590/ S0101-28002010000300005. PMid:21103687.

7. Hoggard J, Saad T, Schon D, Vesely TM, Royer T. Guidelines for venous access in patients with chronic kidney disease. A Position Statement from the American Society of Diagnostic and Interventional Nephrology, Clinical Practice Committee and the Association for Vascular Access. Semin Dial. 2008;21(2):186-91. http://dx.doi.org/10.1111/j.1525139X.2008.00421.x. PMid:18364015.
8. Siddiqui MA, Ashraff S, Carline T. Maturation of arteriovenous fistula: analysis of key factors. Kidney Res Clin Pract. 2017;36(4):31828. http://dx.doi.org/10.23876/j. krcp.2017.36.4.318. PMid:29285424.

9. Konner K, Nonnast-Daniel B, Ritz E. The arteriovenous fistula. $J A m$ Soc Nephrol. 2003;14(6):166980. http://dx.doi.org/10.1097/01. ASN.0000069219.88168.39. PMid:12761270.

10. Demir D, Ceviker K, Aydin M, Sahinalp S. Complications of arteriovenousfistula with polytetraflouroethylen grafts in hemodialysis patients. Niger $\mathrm{J}$ Clin Pract. 2015;18(1):120-3. PMid:25511356.

11. Lee T, Barker J, Allon M. Needle infiltration of arteriovenous fistulae in hemodialysis: risk factors and consequences. Am J Kidney Dis. 2006;47(6):1020-6. http://dx.doi. org/10.1053/j.ajkd.2006.02.181. PMid:16731297.

12. Zambonato $T$, Thomé $F$, Gonçalves $F$. Perfil socioeconômico dos pacientes com doença renal crônica em diálise na região noroeste do Rio Grande do Sul. J Bras Nefrol. 2008;30(3):192-9.

13. Allon M, Ornt DB, Schwab SJ, Rasmussen C, Delmez JA, Greene $\mathrm{T}$, et al. Factors associated with the prevalence of arteriovenous fistulas in hemodialysis patients in the HEMO study. Hemodialysis (HEMO) Study Group. Kidney Int. 2000;58(5):217885. http://dx.doi.org/10.1111/j.15231755.2000.00391.x. PMid:11044239.

14. Martins L, França A, Kimura M. Qualidade de vida de pessoas com doença crônica. Rev. LatinoAm. Enfermagem. 1996;4(3):5-18. http://dx.doi.org/10.1590/S010411691996000300002.

15. Almeida APSC, Nunes B, Duro $S$, Facchini LA. Socioeconomic determinants of access to health services among older adults: a systematic review. Rev Saude Publica. 2017;51:509. http://dx.doi.org/10.1590/ S1518-8787.2017051006661. PMid:28513761.
16. Tortora G. Princípios de anatomia e fisiologia.14. ed. Rio de Janeiro: Guanabara Koogan; 2016.

17. Allon M, Work J. Acesso vascular para hemodiálise. In: John TD, Peter GB, Todd SI, editores. Manual de diálise. 4. ed. Rio de Janeiro: Guanabara Koogan; 2008.

18. Asano M, Thumma J, Oguchi K, Pisoni RL, Akizawa T, Akiba $\mathrm{T}$, et al. Vascular access care and treatment practices associated with outcomes of arteriovenous fistula: international comparisons from the Dialysis Outcomes and Practice Patterns Study. Nephron Clin Pract. 2013;124(1-2):23-30. http:// dx.doi.org/10.1159/000353733. PMid:24029920.

19. Manns B, Tonelli M, Yilmaz S, Lee H, Laupland K, Klarenbach S, et al. Establishment and maintenance of vascular access in incident hemodialysis patients: a prospective cost analysis. J Am Soc Nephrol. 2005;16(1):201-9. http://dx.doi. org/10.1681/ASN.2004050355. PMid:15563567.

20. Rayner HC, Pisoni R, Gillespie B, Goodkin D, Akiba T, Akizawa $\mathrm{T}$, et al. Creation, cannulation and survival of arteriovenous fistulae: data from the Dialysis Outcomes and Practice Patterns Study. Kidney Int. 2003;63(1):323-30. http://dx.doi.org/10.1046/j.15231755.2003.00724.x. PMid:12472799.

21. Fontseré $N$, Caro $P$, Martí $A$, Roca R, Ibeas J, Pozo J, et al. Capítulo 3: cuidados de la fístula arteriovenosa. España: Sociedad Española de Radiología Vascular e Intervencionista; 2016 [cited 2018 May 10]. Available from: https://servei. org/wp-content/uploads/Capitulo_3. docx

22. Robbin ML, Chamberlain NE, Lockhart ME, Gallichio MH, Young CJ, Deierhoi $\mathrm{MH}$, et al. Hemodialysis arteriovenous fistula maturity: US evaluation. Radiology. 2002;225(1):59-64. http:// dx.doi.org/10.1148/radiol.2251011367. PMid:12354984. 